\title{
Data ingestion and assimilation in ionospheric models
}

\author{
Dalia Buresova ('), Bruno Nava $\left({ }^{2}\right)$, Ivan Galkin $\left({ }^{3}\right)$, Matthew Angling $\left({ }^{(}\right)$,
}

Stanimir M. Stankov $\left({ }^{5}\right)$ and Pierdavide Coisson $\left({ }^{2}\right)$

( ${ }^{1}$ Institute of Atmospheric Physics, Academy of Sciences of the Czech Republic, Prague, Czech Republic

$\left({ }^{3}\right)$ The Abdus Salam International Centre for Theoretical Physics (ICTP), Trieste, Italy

( $\left.{ }^{3}\right)$ Centre for Atmospheric Research, University of Massachusetts, Lowell, USA

(4) Centre for Propagation and Atmospheric Research, QinetiQ, Malvern, UK.

$\left({ }^{5}\right)$ Royal Meteorological Institute, Brussels, Belgium

\begin{abstract}
Current understanding of the ionospheric behaviour has been obtained through different observations, modelling and theoretical studies. Knowledge of the ionospheric electron density distribution and its fluctuations, high quality data sets, as well as reliable data ingestion and assimilation techniques are essential for models predicting ionospheric characteristics for radio wave propagation and for other applications such as satellite tracking, navigation, etc., to mitigate the ionospheric effects on radio wave propagation. Effect of the ionosphere on Global Navigation Satellites System (GNSS) accuracy is one of the main factors limiting the reliability of GNSS applications. In accord with the objectives of the European COST 296 project, (Mitigation of Ionospheric Effects on Radio Systems, MIERS) under an international collaboration some new results have been achieved in collecting and processing high quality ionospheric data, in adaptation of the ionospheric models to enable data ingestion and assimilation, and in validation and improvement of real-time or near-real time ionospheric ionisation electron density reconstruction techniques.
\end{abstract}

Key words Ionosphere - models - data assimilation - data ingestion

\section{Introduction}

To mitigate ionospheric effects on radio propagation, we must know when, where and how strong these effects will be, i.e. we need to predict them. A very promising and modern way of improving the model performance and prediction capabilities is to use specific data assimilation procedures and prediction tech-

Mailing address: Dr. Dalia Buresova. Institute of Atmospheric Physics, Academy of Sciences of the Czech Republic, Department of Aeronomy, Borni Il 1401, 14131 Prague 4, Czech Republic; e-mail: buresd@ufa.cas.cz niques. Indeed, the development and the validation of such models and techniques addressed a number of problems, like the necessity of having high quality observational data of different kind that have been analysed in the WP1.2 «Data ingestion and assimilation in ionospheric models».

Collaborative ground-based HF radio sounding of the ionosphere is a successful example of international cooperation at multiple observatories around Europe (and beyond) that accomplishes unsurpassed accuracy, detail, coverage, and real-time availability of the ionospheric environment specification. A bigticket item in the HF sounding approach has been the human expertise needed to accurately derive ionospheric specification data from raw ionogram images. Use of the ionosonde data in operational space weather systems became pos- 
sible due to a strenuous effort to automate the ionogram scaling process (Reinisch and Huang, 1983). Until very recently, however, use of the real-time autoscaled data in the operational ionospheric modelling had been uninformed by the associated uncertainties of the automatically derived characteristics. Besides automatic scaling of ionograms at some European stations like El Arenosillo, Ebro and Pruhonice, a routine handy control and corrections of ionogram scaling are made, which provides data in quality suitable not only for service but also for accurate scientific analyses.

The German Aerospace Center (DLR) established a space weather monitoring service (SWACI) focused on GNSS positioning applications (Jakowski et al., 2005; 2006). Part of this service includes the use of a European regional TEC model NTCM (Neustrelitz TEC Model) for forecast purposes. TEC short-term forecast maps for non-storm conditions are generated using the latest TEC values and the gradients estimated by the NTCM model. Thus, real-time measurement information is merged with the experience acquired from previous measurements via NTCM use. In addition, an immediate correction to this forecast is applied taking into account the geomagnetic activity influence on the TEC variations (Stankov and Jakowski, 2006).

The Electron Density Assimilative Model (EDAM) provides a means to assimilate ionospheric measurements in a background ionospheric model. The assimilation is based on a weighted, damped least mean squares estimation. This is a form of minimum variance optimal estimation (also referred to as Best Linear Unbiased Estimation, BLUE) that provides an expression for an updated estimation of the state (known as the analysis) that is dependent on an initial estimate of the state (the background model), and the differences between the background model and the observations. The error covariance matrices of the background model and the observations are also included to control the relative contributions of the background and the observations to the analysis.

Concerning the data ingestion in ionospheric models, it is worth mentioning the schemes that have been developed at the Aeronomy and
Radiopropagation Laboratory (ARPL) of the Abdus Salam International Centre for Theoretical Physics (ICTP) in order to adapt empirical median models, like IRI or NeQuick, simultaneously to actual GPS-derived TEC data and ionosonde measured peak parameters. These near-real-time techniques are based on the use of effective parameters (Nava et al., 2005; 2006a; 2006b) and are able to improve the model capabilities to give time-dependent specifications of the three-dimensional electron density of the ionosphere.

Chapter 2 presents the results of work done to support ionospheric modelling with data sets of higher quality. In Chapter 3, the results of validation of the selected models, data ingestion and assimilation techniques are outlined and the main follow-up improvements are described. Chapter 4 gives the recent results on development and improvements of real-time or near-real-time electron density reconstruction techniques.

\section{Results on determination and collection of additional data products to improve support for ionospheric modeling}

This section describes the work done to support ionospheric modelling with high quality data sets.

\subsection{HF radio sounding in support of ionospheric modelling}

With the advent of ionospheric assimilation models that carefully consider the sensor data errors, the need to qualify the uncertainty of ingested ionogram-derived data has become apparent and pressing. Another step forward on the path of describing errors of the ionogram autoscaling for the optimal assimilation of ionosonde data was made in 2006-2008. With extensive contributions from the research teams affiliated with COST 296 action, a major statistical comparison study of the autoscaled data was conducted using over 250,000 manually scaled ionograms. The statistical study allowed us not only to validate the stream of real-time 
ionogram-derived data, but also to improve existing practices of its assimilation by formulating additional data attributes such as the $\mathrm{Au}$ toscaling Confidence Level (ACL), error bars for derived ionospheric characteristics, and uncertainty boundaries for the electron density profile (EDP).

\subsubsection{Autoscaling Confidence Level (ACL)}

New version 5 of the ARTIST software (Galkin et al., 2008a) is now available for digisonde ionospheric sounders. The new software is able to self-diagnose ionogram interpretation failures and label low-confidence ionogram scaling results accordingly so that they can be excluded from the assimilation process, or included at an appropriately specified high uncertainty. Analysis of the ARTIST 5 performance at European locations shows that it normally labels not more than $10-15 \%$ of all ionograms with the «ACL $=0$ » flag indicating the low confidence of the automatic analysis. Software modifications are being implemented for digisondes to replace the $\mathrm{ACL}=0$ records with an «insufficient quality»message so as to eliminate most evident errors of the automatic interpretation from the assimilation process.

\subsubsection{Automatic evaluation of spread $F$ condition}

lonograms that display signatures of multipath propagation during spread $F$ conditions are more difficult to interpret automatically. Classification of ionograms by the level of ionospheric disturbance opens opportunities for a better processing and integration of the autoscaled data in the ionospheric models. A spread $F$ detection algorithm is now included in the ARTIST 5 software to assign three levels of disturbance to each ionogram: (i) quiet, (ii) moderate, and (iii) heavy. Qualification of the autoscaled data errors is then done separately for each category.

\subsubsection{Error bars for autoscaled ionospheric characteristics}

Provision of the error bars (uncertainty bounds) with the autoscaled characteristics is required by the operational ionospheric models based on assimilation principles, as it confines the Kalman filter to seek the optimal match of the model and sensor data within the given bounds. The error bars for ionogram-derived characteristics are determined statistically by evaluating the differences between the au-

Table I. ARTIST 5 validation results for $f o F 2$ scaling at various mid-latitude locations. Error bounds are given at $95 \%$ probability level for ionograms in quiet-and-confident category.

\begin{tabular}{lcccccc}
\hline \hline Location & System & $\begin{array}{c}\text { Total } \\
\text { manual } \\
\text { ionograms }\end{array}$ & $\begin{array}{c}\text { ACL=1 \% } \\
\text { of all } \\
\text { ionograms }\end{array}$ & $\begin{array}{c}\text { Lower } \\
\text { bound } \\
\text { foF } 2 \\
\mathbf{M H z}\end{array}$ & $\begin{array}{c}\text { Upper } \\
\text { bound } \\
\text { foF2 } \\
\text { MHz }\end{array}$ & $\begin{array}{c}\text { Unscalable } \\
\text { ionograms } \\
\text { \% of all } \\
\text { ionograms }\end{array}$ \\
\hline Rome, Italy & DPS-4 & 4,251 & $83 \%$ & -0.25 & +0.35 & $7 \%$ \\
Grahamstown, South Africa & DPS-4 & 5,251 & $85 \%$ & -0.1 & +0.2 & $1 \%$ \\
Juliusruh, Germany & DPS-4 & 6,000 & $70 \%$ & -0.2 & +0.25 & $4 \%$ \\
Roquetes, Spain & D-256 & 125,046 & $85 \%$ & -0.3 & +0.4 & $5 \%$ \\
Dyess, USA & DISS & 6,881 & $90 \%$ & -0.3 & +0.5 & $3 \%$ \\
Boulder, USA & DISS & 47,261 & $84 \%$ & -0.25 & +0.3 & $7 \%$ \\
Pruhonice, Czech Republic & DPS-4 & 20,675 & 88 & $\%-0.15$ & +0.35 & $3 \%$ \\
\hline
\end{tabular}



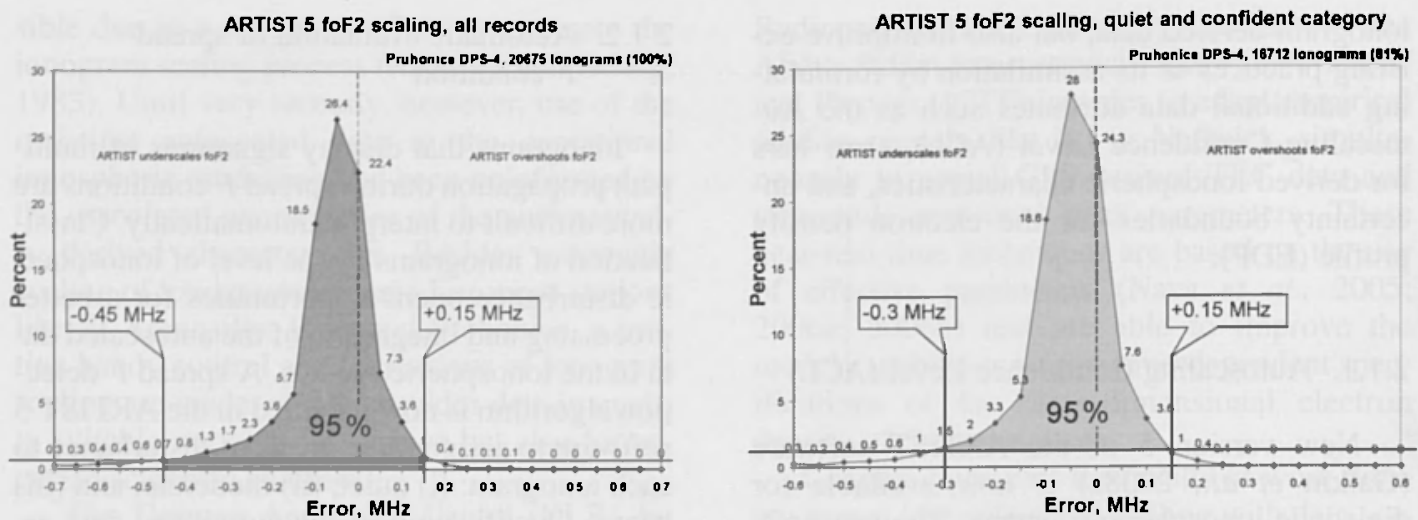

Fig. 1. (Left panel) Error histogram of autoscaled critical frequencies of $F 2$ layer obtained for 20675 ionograms from DPS-4 ionosonde at Pruhonice, Czech Republic. 95\% of all autoscaled values lie within the -0.45 to +0.15 $\mathrm{MHz}$ interval from the true values provided by manual scalers. (Right panel) Error histogram for quiet ionospheric conditions and high confidence of autoscaling. Lower bound for foF 2 has improved from -0.45 to -0.3 $\mathrm{MHz}$ in comparison to the all ionogram case.

toscaled and manually scaled values and then defining the upper and lower bounds, which encapsulate $95 \%$ of all cases. Thus determined error bars ensure $95 \%$ probability that the true value lies between the given bounds around the autoscaled value. Figure I shows two examples of the error histogram for the critical frequency fo $F 2$, obtained for 20,675 manually scaled Pruhonice DPS-4 ionograms. To determine the lower and upper uncertainty bounds, a horizontal line is drawn across the histogram plot and then lowered until percentage of ionograms between two intersections of this line with the error distribution curve becomes $95 \%$.

The left panel of fig. I shows the histogram calculated for all ionograms in the study. The right panel illustrates quality improvement accomplished by classification of ionograms using automatically determined levels of ionospheric disturbance and autoscaling confidence. 95\% uncertainty bounds for autoscaled foF 2 obtained during quiet conditions and high confidence $(81 \%$ of all cases) are $-0.15 \mathrm{MHz}$ to $+0.3 \mathrm{MHz}$.

Table I lists validation results for several contributing mid-latitude digisonde stations. The foF 2 error bars are similar at all locations, with slightly better results obtained for the
DPS- 4 model of the digisonde. About $1-7 \%$ of all ionograms could not be used to scale foF 2 value for valid reasons such as blanketing by the sporadic $E$-layer or $D$-layer absorption. Accounting for the unscalable ionograms, the total percentage of ionograms that fail the ARTIST confidence check and therefore shall not be assimilated varies between 7 and $14 \%$ of all ionograms, with one exception of Juliusruh observatory $(26 \%)$ whose data traditionally poses higher challenge for correct interpretation.

\subsubsection{Uncertainty boundaries for autoscaled electron density profile}

Further improvement of the ionogram-derived data assimilation process has been accomplished by determining the uncertainty of each provided electron density profile point (Galkin et al., 2008a).

In order to specify $\Delta N$ at each height, two boundary profiles, inner and outer, are constructed (fig. 2). The inner and outer boundaries reflect the uncertainties of the critical frequencies $\Delta f_{\text {cr }}$ of each layer, the internal uncertainty of the starting height of the profile, and the uncertainties of the $E$ valley model representation. 


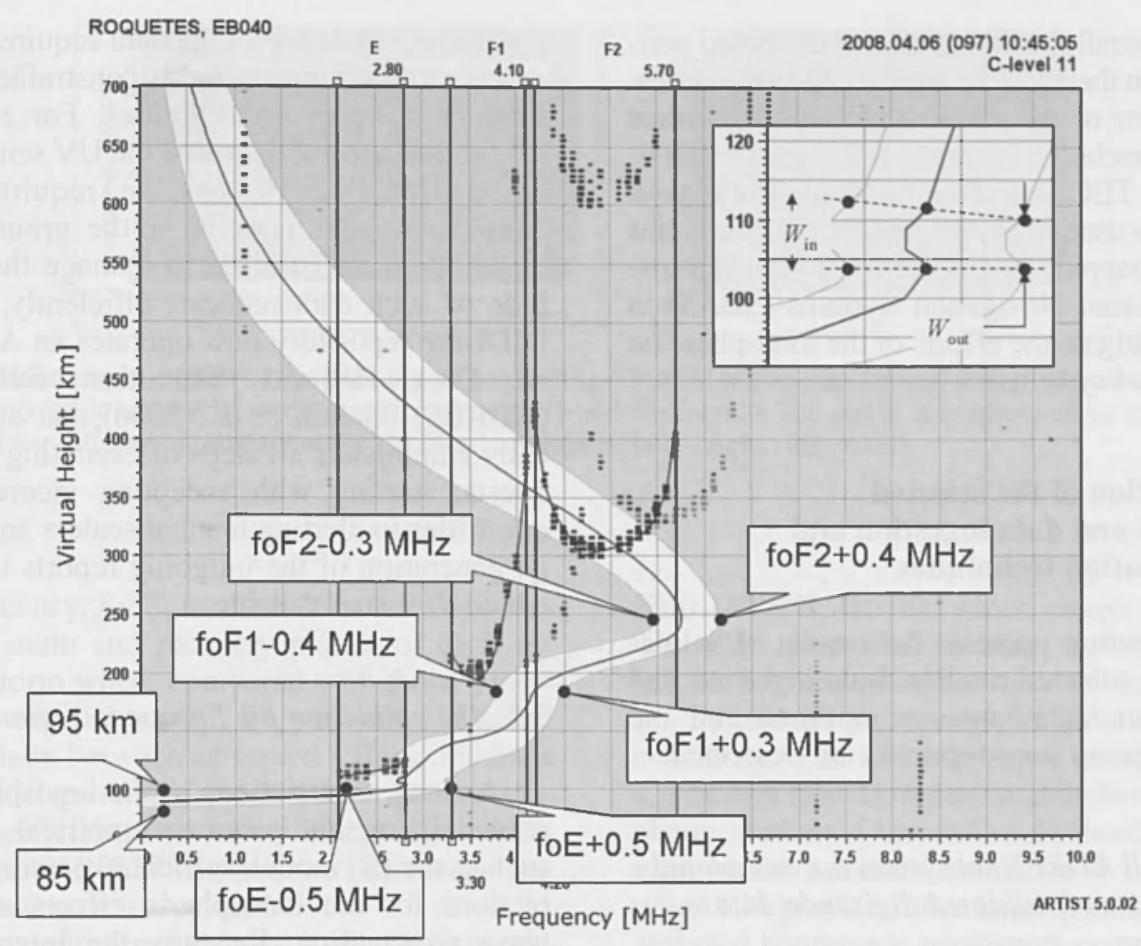

Fig. 2. Autoscaled ionogram from Roquetes, Spain, with inner and outer uncertainty boundaries for calculated electron density profile. The uncertainty boundaries are obtained by modifying the original profile coefficients so that the boundary fits the anchor points as indicated. Uncertainties of $f o E, f o F 1$, and $f o F 2$ critical frequencies are specific to the quiet confident ionograms at Roquetes.

\subsubsection{SAOXML: ionosonde data exchange format}

The Standard Archiving Output (SAO) format has been operational since 1987 in the capacity of the URSI-recommended standard for ionogram-derived data. Addition of new data elements for the assimilation models, the uncertainty boundaries for EDP and ionospheric characteristics, motivated the SAO design team to reconsider existing format vehicle and formulate a new standard (Galkin et al., 2008b) based on the XML language for data exchange and the SAO heritage. The data model and format syntax of the SAOXML were widely discussed in the COST 296 community and accepted for preliminary testing at the DIAS, a
pan-European ionospheric predictions system operated at the National Observatory of Athens.

\subsection{High quality TEC data}

Concerning the TEC data, during the COST 296 action, L. Ciraolo of IFAC, Florence, Italy, provided a set of high quality slant TEC data. This dataset contains TEC data at 30 seconds time interval obtained for the period 20 September-31 October 2001 from about 50 ground stations located in Europe. As can be seen from the web page of the World Data Centre for Geomagnetism, Kyoto (http://swdcwww.kugi,kyotou.ac.jp/index.html) these data correspond to both 
geomagnetically undisturbed and disturbed periods and can therefore be used to study the general behaviour of the ionosphere electron content and the correlation between geomagnetic activity and the TEC at a given location. The dataset can be also used to investigate specific problems like the «mapping function errors» related to the Satellite Based Navigation Systems (SBAS) in order to mitigate the effects of the ionosphere on such kind of systems.

\section{Validation of the selected models and data ingestion and assimilation techniques}

This section presents the results of validation of the selected models. Data ingestion and assimilation techniques are outlined and the main follow-up improvements are described.

\subsection{Lowell ADRES subsystem for automated requests of validated digisonde data}

Validation of the ionospheric models and associated ingestion/assimilation techniques is best performed using high quality «ground truth» datasets. Acquiring such reference datasets incurs the expense of voluminous data analysis and requires a unique instrument and data interpretation expertise. Over the past three years, an increasing roster of the validated ionospheric data has been available from the Lowell Digital Ionogram Database (DIDBase) repository (Khmyrov et al., 2008) holding manually scaled ionogram data. Generous contributions of edited ionograms to the DIDBase have been recently made from Roquetes and Pruhonice digisondes operating in Europe, totaling $\sim 150,000$ interpreted measurements. With these contributions, current DIDBase collection of manually validated reference datasets has exceeded the $600 \mathrm{~K}$ ionogram mark.

Considering the high value of the reference datasets derived from ionograms, validation projects are commonly arranged to constrain needed reference datasets to particular events only, in which case the requested coverage periods, though small, can be quite numerous. In particular, validation of the data acquired by the spacecraft instrumentation is constrained to the satellite overpass opportunities. For example, calibration and validation of the UV sensors onboard DMSP F-16 satellite required over 25,000 one-hour periods of the ground truth digisonde data. In order to manage the multitude of such data requests efficiently, Lowell DIDBase repository now operates an Automated Data Request Execution Subsystem (ADRES) (Galkin et al., 2006) that automatically administers all steps of executing data requests, starting with accepting incoming request files to alerting manual scalers and, finally, generation of the outgoing reports once the edited data are available.

\subsection{IRI validation for European region}

As long as variations in the ionosphere are related in regular patterns, empirical models, such as the IRI model, sufficiently estimate corrections for the ionospheric effects on radio wave propagation. Recently the International Reference Ionosphere model (starting from version IRI 2001) incorporated a geomagnetic activity dependence based on an empirical StormTime Ionospheric Correction Model (STORM), which is driven by an index derived from the previous thirty hours of geomagnetic activity (Araujo-Pradere et al., 2002). The output of the model provides a correction to the quiet-time $F$ region peak critical frequency under geomagnetically disturbed conditions.

\subsubsection{STORM model validation}

In the frame of the COST 296 project the STORM model was verified for European middle latitudes under strong-to-severe geomagnetic storm conditions. The created database incorporated 65 strong-to-severe geomagnetic storms, which occurred within the period 19952007. The analysis also used data from some ionospheric stations (e.g., Pruhonice, El Arenosillo, Athens), which were not included in the development or the previous validation of the model. Hourly values of the $F 2$ layer criti- 

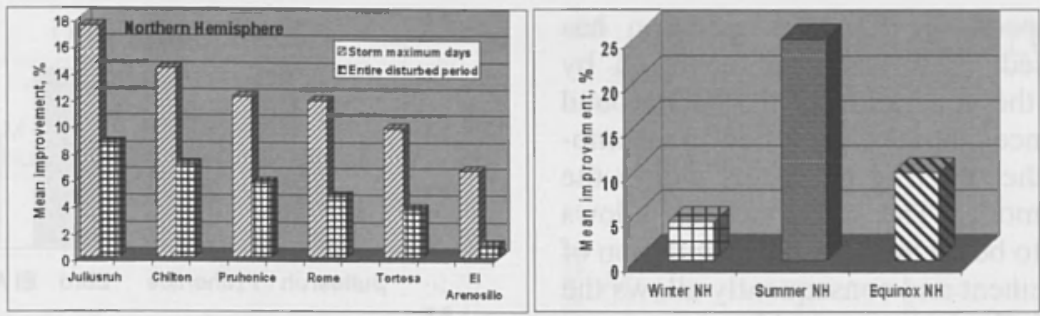

Fig. 3. Mean improvement of the IRI outputs comparing STORM off/on options and ionosonde observations for five European ionospheric stations (left side panel) and the results for storm maximum days of all events analysed for different seasons and for the Northern hemisphere (right side panel).

cal frequency, $f o F 2$, measured for 5-7 days during the main and recovery phases of each selected storm where compared with those generated by the IRI model. To perform a detailed comparison between observed values, medians and model-generated $f o F 2$ values the correlation coefficient, the normalised root-meansquare error (NRMSE), and the percentage improvement were calculated.

The results are presented in fig. 3 . In general, the comparative analysis showed that the STORM model captures more effectively the negative phases of the summer ionospheric storms, while electron density enhancement during winter storms and changeover of the different storm phases is reproduced with lower accuracy (Buresova et al, 2008).

\subsubsection{Improvement and validation of the IRI-200I ionospheric bottomside representation}

IRI-2001 model still has large discrepancies for ionospheric $F$ region bottomside parameters $B O, B I$ and $D I$, probably due to the present tabular form of IRI for these parameters. In 2005 a Local Model (LM) was developed to improve model predictions of the above parameters based on a least-square fitting to a harmonic function that simulates the diurnal, semidiurnal and seasonal variations according to different levels of solar activity under quiet conditions (Blanch $e t$ al., 2007). The LM was created using the retrospective data set of European mid-latitude station
Ebro $\left(40.8^{\circ} \mathrm{N}, 0.5^{\circ} \mathrm{E}\right)$, which covers more than one solar cycle. The Monthly Averaged Representative Profile (MARP) was used to obtain the $B O, B I$ and $D I$ parameters for quiet ionospheric conditions. The LM was tested using manually scaled data from European middle latitude ionospheric stations (Arenosillo, Pruhonice, Juliusruh). Model validation results show that the proposed LM provides more reliable variation of the analysed bottomside parameters comparing with those IRI-2001-generated. At mid-latitudes and under quiet ionospheric conditions LM allows an improvement of the IRI2001-predicted coefficients $B O$ and $B I$ at an average by factor of two and improvement of the parameter $D I$ predictions by factor of three (fig. 4).

\subsection{The Electron Density Assimilative Model (EDAM): system improvement and validation}

Currently, EDAM can assimilate ground based total electron content (TEC) measurements, space based radio occultation measurements, vertical electron density profiles (i.e. from ionosondes) and point electron density measurements (i.e. from Langmuir probes).

\subsubsection{The EDAM improvement}

Over the course of the COST 296 programme, the development of EDAM has continued. Of particular note are the following: 
1. The speed of EDAM's operation has been increased. This has been achieved by speeding up the generation of the background error covariance matrices and relies on assumptions about the ordering of voxels within the background model. The speed increase allows more voxels to be included in the asimilation of each measurement and consequently allows the data to have influence over a wider area.

2. The scale lengths used in generating the co-variances have also been enhanced and now allow for a full 3D specification of scale length in latitude, longitude and altitude.

3. Either IRI 2007 or PIM may be used as the EDAM background model.

4. The primary background model variable has been changed from electron density to the $\log$ of the electron density. This reduces the dynamic range of the background model, forces the analysis to be positive definite and allows the use of variances that better conform to the assumptions implicit in the assimilation (i.e. that the errors are Gaussian). The change has markedly increased the stability of the assimilation.

5. EDAM maintains a rolling six hour store of data from each input GPS station. This is used to reduce noise in the phase levelling process that is used to calculate slant TEC.

6 . The noise in on the pseudorange measurements is estimated and used to set the measurement variance.

7. User generated receiver differential code biases can now be included.

\subsubsection{The EDAM validation}

Numerous tests have been conducted to investigate the performance of EDAM. Brief summaries of some of these tests are included here. Angling and Khattatov (2006) describe comparative testing using EDAM and IonoNumerics (Khattatov et al., 2004; 2005). The comparative testing was conducted with identical input data sets (GPS data) and test data sets (ionosonde data). The results were examined as a function of magnetic latitude and distance to the nearest input data point. For example, fig. 5 shows the foF 2 RMS errors for all the test
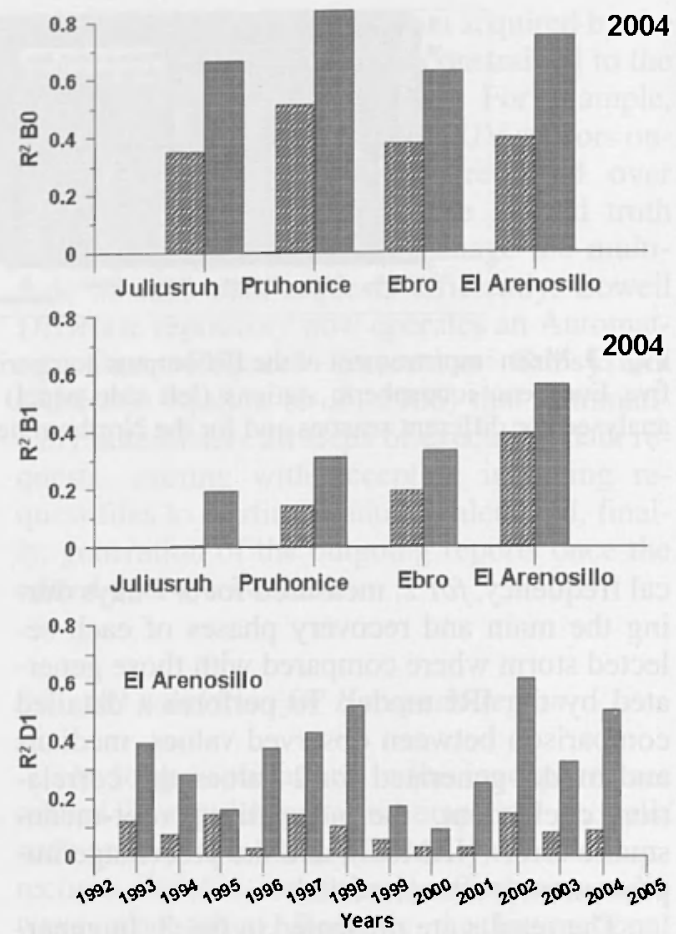

Fig. 4. Comparison of the linear coefficient of determination $R^{2}$ for IRI2001 model-predicted (forward slashed bars) and LM-calculated (grey bars) parameters $B O$ and $B I$ for four European stations (upper and middle panels) for 2004 . Bottom panel represents $R^{2}$ obtained for $D l$ El Arenosillo for different solar activity.

ionosondes as a function of magnetic latitude. The data has been split into two groups by local time (06:00-17:59 and 18:00-05:59) at each ionosonde site. As might be expected the errors are worst at low and high latitudes where ionospheric variability is likely to be greatest.

Angling (2008b) describes the assimilation of radio occultation data from the COSMIC satellite constellation into EDAM. Initial testing shows the positive effect of including $\mathrm{RO}$ data within the assimilation. For example, fig. 6 shows the RMS error between vertical profiles extracted from EDAM (and PIM) and ionosonde vertical profiles at $5 \mathrm{~km}$ height steps on 4 September 2006 (moderate geomagnetic conditions). However, at the time of the test, the COSMIC satellite constellation had not yet been spread to its operational 

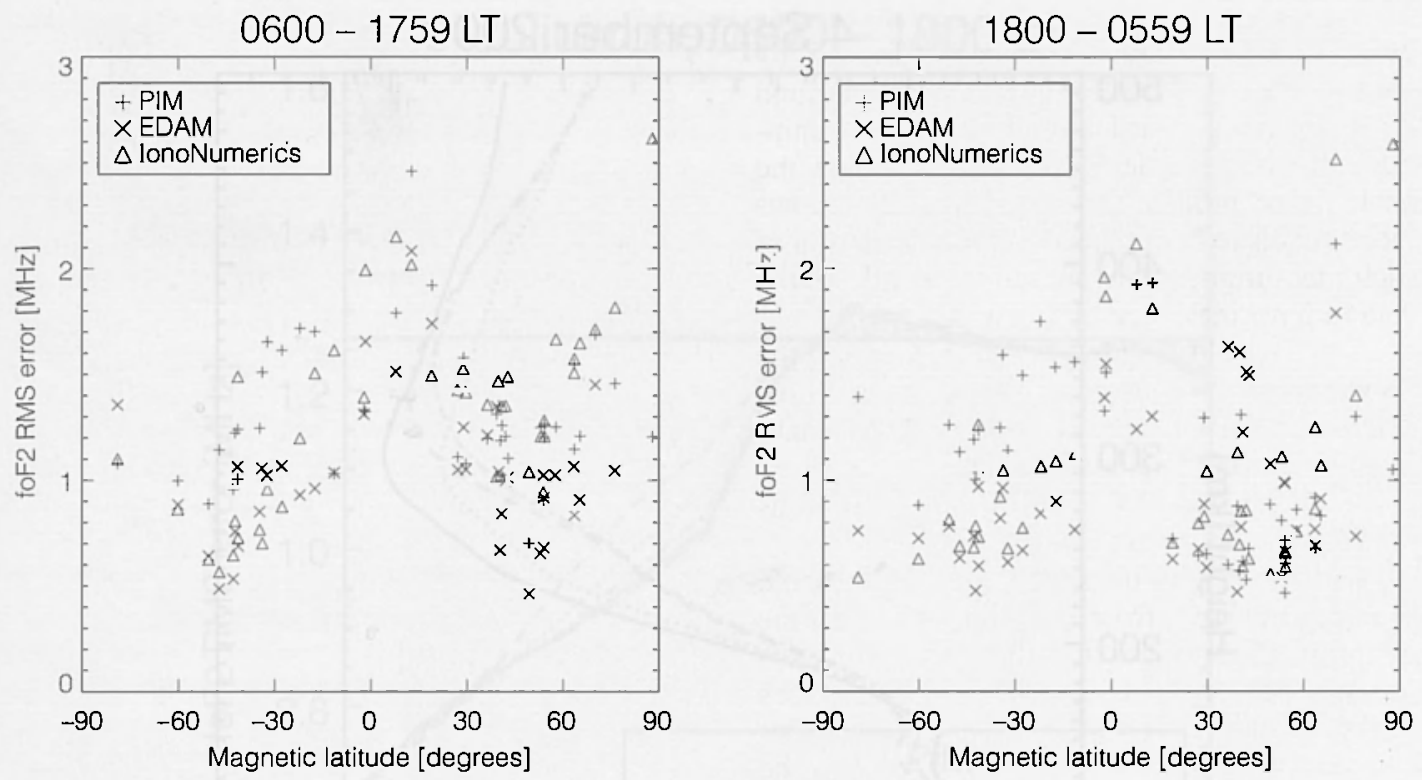

Fig. 5. foF2 RMS error as a function of magnetic latitude (from Angling and Khattatov, 2006).

configuration, so the full impact of the system could not be fully determined.

Tests against ionosonde data have also been conducted to investigate the forecasting performance of EDAM (Angling and Cannon, 2006). These tests have compared measured vertical ionosonde $f o F 2$ data with foF 2 forecasts from EDAM. Figure 7 shows an example of EDAM foF2 forecasts tested against data from the Juliusruh ionosonde (daytime data only). Forecasts have been run from zero to twelve hours for a range of scale times (tau). Results support the view that EDAM forecasts are only likely to be effective up to a few hours in the future.

Angling and Cannon (2006) describe a number of $\mathrm{HF}$ communications applications based on EDAM. More recently, a web-based $\mathrm{HF}$ frequency management tool has been developed (EDAM533) (Angling et al., 2008). This combines the EDAM real time ionospheric model with an implementation of ITU-R Rec533 to provide guidance to HF operators (fig. 8). Further details of the model can also be found in Angling and Khattatov (2006).

\subsection{The NeQuick model}

The NeQuick is a quick-run ionospheric electron density model designed for transionospheric propagation applications. It is based on the DGR «profiler» proposed by Di Giovanni and Radicella (1990) and subsequently modified by Radicella and Zhang (1995). The new version (2) of the model has recently been finalized (Nava et al., 2008). It includes major changes in the representation of the topside (Coïsson et al., 2006) and in the bottomside (Leitinger et al., 2005) of the ionosphere.

To describe the electron density of the ionosphere above $100 \mathrm{~km}$ and up to the peak of the $F 2$ layer, the NeQuick uses a modified DGR profile formulation (Radicella and Leitinger, 2001), which includes five semi-Epstein layers with modelled thickness parameters. Three profile anchor points are used: the $E$ layer peak, the $F 1$ peak and the $F 2$ peak, that are modelled in terms of the ionosonde parameters foE, foFl, foF2 and $M(3000) F 2$. These values can be modelled (e.g. ITU- R coefficients for foF 2 , M3000) or experimentally derived. The semi- 


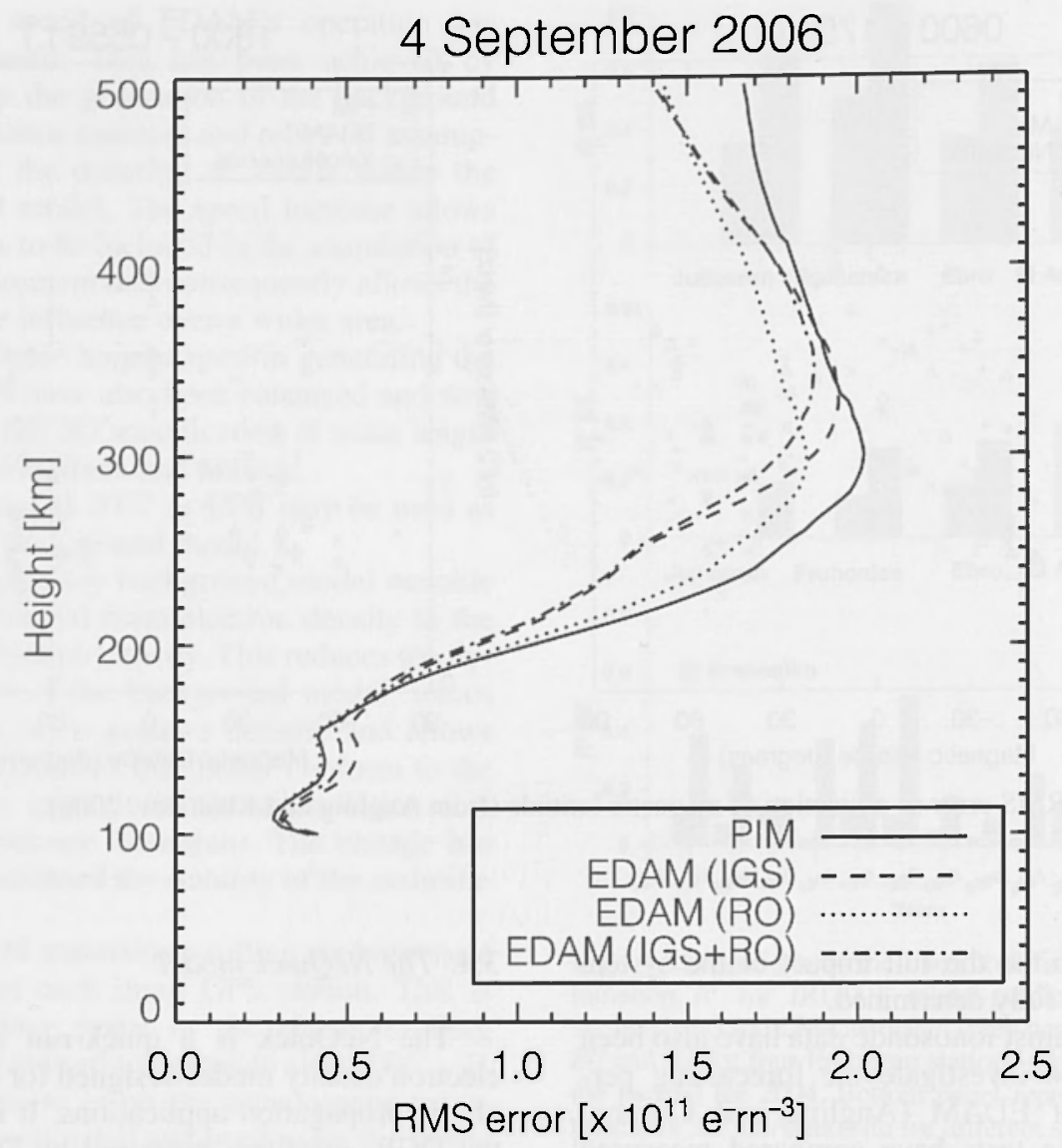

Fig. 6. RMS error between ionospheric models and ionosonde vertical profiles at $5 \mathrm{~km}$ height steps on 4 September 2006 (moderate geomagnetic conditions). The models are: PIM (solid line); EDAM assimilating IGS data only (dashed line); EDAM assimilating COSMIC RO data only (dotted line); and EDAM assimilating IGS and COSMIC RO data (dot-dash line) (from Angling, 2008b).

Epstein layer represents the model topside with a height-dependent thickness parameter empirically determined (Hochegger et al., 2000). The NeQuick package includes routines to evaluate the electron density along any ray-path and the corresponding Total Electron Content (TEC) by numerical integration.

Considering the mitigation of ionospheric effects on Satellite Navigation Systems is worth noting that the first version of the model has been used by the European Space Agency (ESA) European Geostationary Navigation Overlay Service (EGNOS) project for assess- ment analysis. In particular the model has been used to produce synthetic TEC data to investigate problems related to the integrity and the availability of the Service.

The NeQuick has been adopted for singlefrequency positioning applications in the framework of the European Galileo project and it has also been adopted by the International Telecommunication Union, Radiocommunication Sector (ITU-R) as a suitable method for TEC modelling. In addition, the NeQuick has been implemented in the simulation toolkit developed in Australia to conduct a qualitative assessment of 


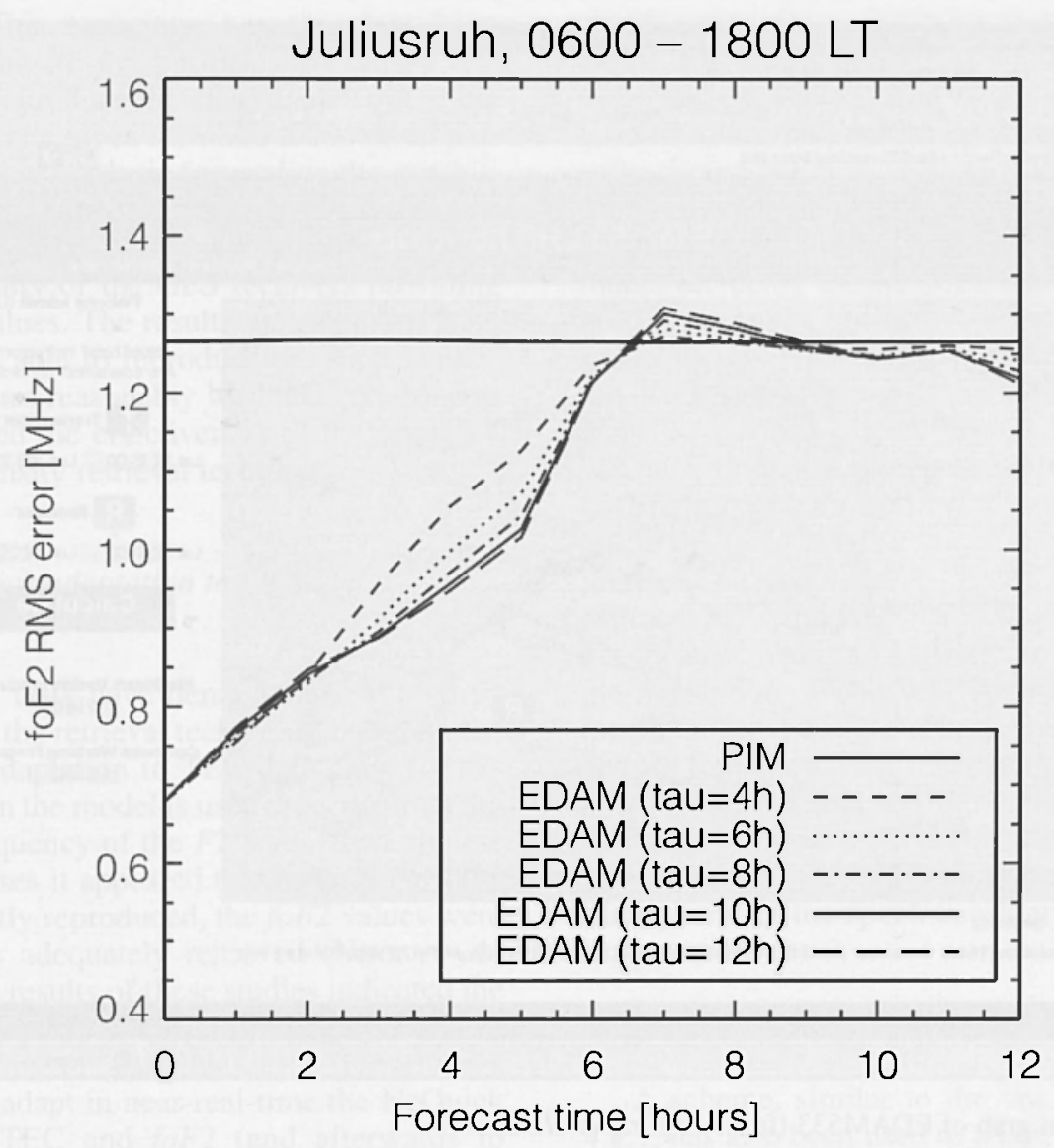

Fig. 7. Example foF 2 forecast performance of EDAM. Results are shown for a range of scale times (tau) used within the forecasting process (from Angling and Cannon, 2006).

the performance characteristics of the future GNSS infrastructure (Nava et al., 2008).

In the scope of the COST 296 , synthetic electron density data have been produced with the NeQuick model to help develop algorithms to detect gravity waves in the ionosphere and determine their properties in 3-D. As a starting point, a set of electron density values for 24 hours at 10 minute time intervals have been produced for a grid defined by the coordinates $20^{\circ} \mathrm{N}$ to $40^{\circ} \mathrm{N}$ (step $1 \mathrm{deg}$ ); $0^{\circ} \mathrm{E}$ to $30^{\circ} \mathrm{E}$ (step 2 $\mathrm{deg}$ ) and for heights ranging from 100 to 300 $\mathrm{km}$ with $5 \mathrm{~km}$ stepping. Subsequently the same kind of data has been produced with 1-minute time intervals from 12 UT to 18 UT. Synthetic
TEC data have been used to investigate the reliability of a particular calibration technique developed to obtain TEC data from dual frequency GPS receiver.

Using the NeQuick model, ionosphere electron density retrieval techniques based on model adaptation to experimental data have been developed (Nava et al., 2005, 2006a). All these techniques rely on the fact that, for a given epoch and ray-path, the model TEC is a monotonic function of the solar activity index, that can be regarded as an «effective ionisation level» parameter $(\mathrm{Az})$. As a first step, the concept of effective ionisation level has been used to adapt the model to GPS derived vertical and slant TEC 


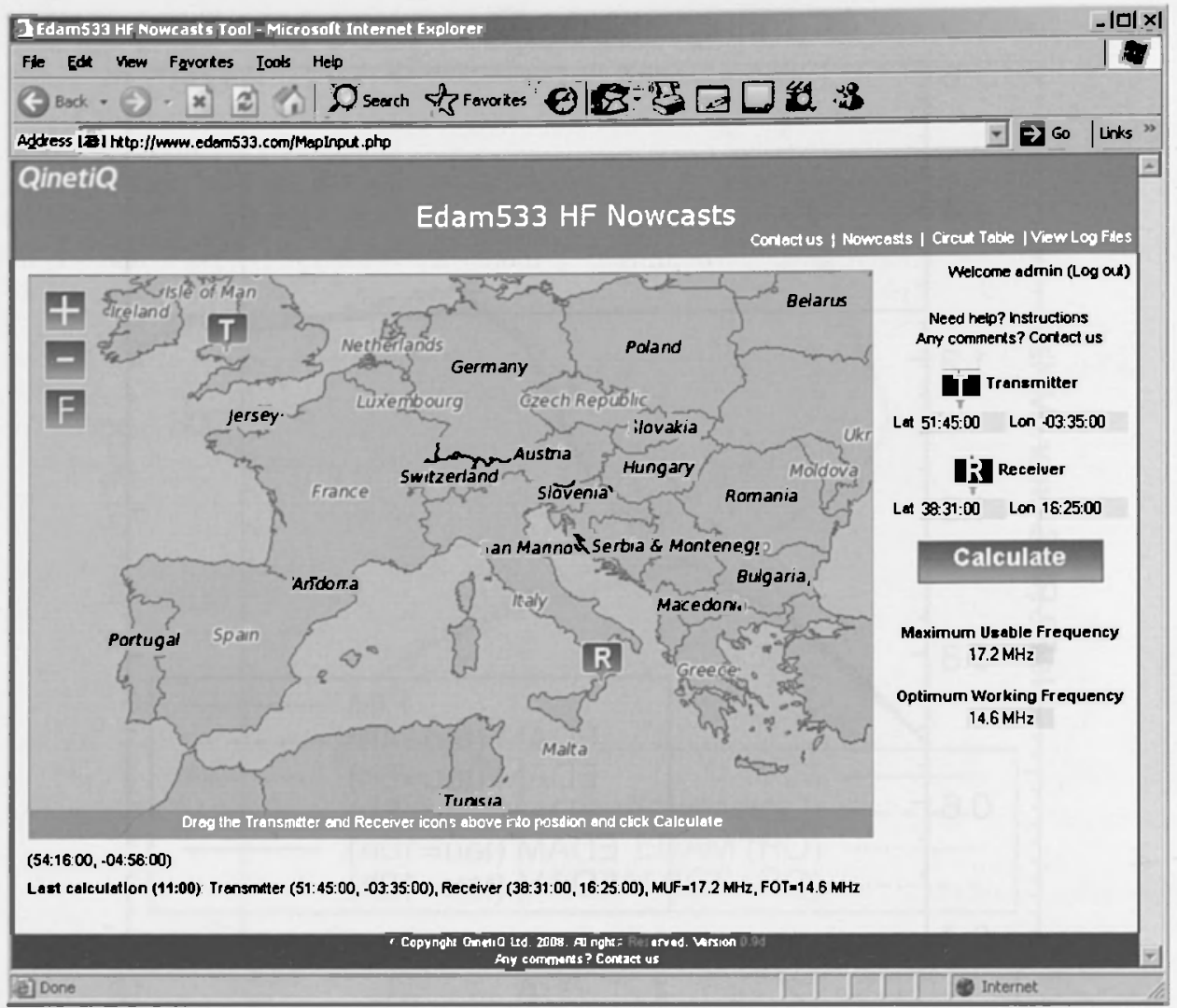

Fig. 8. Screen grab of EDAM533 (from Angling et al., 2008).

only. In the case of adaptation to vertical TEC maps (Nava et al., 2005), the electron density reconstruction method could not be considered a real time procedure, because of the time needed to produce the TEC maps. Nevertheless, the model adaptation to slant TEC data can be performed in near-real time (Nava et al., 2006a).

\section{Results on development and improvements of real-time or near-real-time electron density reconstruction techniques}

This section gives recent results on development and improvement of real-time or near-realtime electron density reconstruction techniques.

\subsection{NeQuick and IRI adaptation to GPS data}

Following the concepts expressed by Komjathy et al. (1998) and Nava et al. (2005, 2006a) a near real-time ionosphere electron density retrieval technique has been elaborated and implemented using both the IRI and the NeQuick models (Nava et al., 2006b). The technique, based on the models adaptation to GPS-derived TEC data obtained from a single ground station, determines the values of the models driving parameters IGeff (for IRI) and $\mathrm{Az}$ (for NeQuick) corresponding to the location and the epoch considered. The knowledge of IGeff and $\mathrm{Az}$ enables IRI and NeQuick respectively to compute the three dimensional electron density of the ionosphere for the geographic area under 
analysis. This technique has therefore been used to evaluate the performance of the two models to reproduce the electron density of the ionosphere at a given time and location. In particular the data analysis focused on the capabilities of the models to retrieve the experimental fo $F 2$ values obtained from ionosondes located in the vicinity of the GPS receivers providing the TEC values. The results indicated that both models are able to reproduce the foF 2 experimental values reasonably well and consequently confirmed the effectiveness of the proposed electron density retrieval technique.

\subsection{NeQuick adaptation to GPS and ionosonde data}

Several tests have demonstrated the effectiveness of the retrieval techniques based on the NeQuick adaptation to TEC data only, for example when the model is used to reconstruct the critical frequency of the $F 2$ layer. Nevertheless in some cases it appeared that, even if the TEC was correctly reproduced, the $f o F 2$ values were not always adequately retrieved (Nava et al., 2007). The results of these studies indicated the need to further improve of the model formulation in terms of slab thickness. Therefore a method to adapt in near-real-time the NeQuick model to TEC and foF2 (and afterwards to $h m F 2$ ) experimental values has been developed on the bases of the effective parameter concept.

\subsubsection{The NeQuick adaptation method}

At a given epoch it is assumed to have a GPS receiver tracking $n$ satellites, thus determining a set of $n$ slant TEC values and an ionosonde (located in the vicinity of the GPS receiver) providing the relevant foF 2 value. Taking advantage of the ITU-R coefficients implemented in the NeQuick model we define as $\mathrm{Az} f o F 2$ the effective ionization level value that allows NeQuick to reproduce the experimental foF 2 value. In a similar way, by means of the Dudeney formula (Dudeney, 1983) for $h m F 2$ implemented in the NeQuick model we define as $\mathrm{Az}_{-} / m \mathrm{mF} 2$ the effective ionization lev- el value that allows NeQuick to reproduce the experimental $h \mathrm{mF} 2$ value. The effective parameters related to foF 2 and $h \mathrm{mF} 2$ are therefore used to constrain the model peak parameters locally. Being the TEC mismodeling the difference between a modelled slant TEC and the related experimental slant TEC, the NeQuick model driven by the $\mathrm{Az} f o F 2$ and $\mathrm{Az} \_h n F 2$ is used to minimize the RMS of the $n$ TEC mismodeling as a function of a correcting factor for the NeQuick bottomside thickness parameter. This additional correcting factor for the NeQuick thickness parameter is therefore used to locally constrain the model slab thickness. It has to be noted that the use of the effective parameters $\mathrm{Az}_{\_}$foF 2 and $\mathrm{Az}_{-} h m F 2$ is required to estimate foF 2 and $h \mathrm{mF} 2$ values with the ITU-R coefficients over a region surrounding the ground station. In this way the model peak parameters can be estimated for all the points needed for a slant TEC computation. The effective parameters and the correcting factor can therefore be inserted into NeQuick in order to (locally) retrieve the $3 \mathrm{D}$ electron density of the ionosphere for the epoch considered.

\subsubsection{The IRI adaptation method}

A scheme, similar to the one described in 4.2.1, has also been used to adapt the IRI model to experimental TEC values and ionosonde peak parameters. In particular, in the case of IRI, the experimental values of foF 2 and $h \mathrm{mF} 2$ have been directly used as input and the concept of effective parameter has not been applied. Nevertheless, the same modulating coefficient has been applied to IRI bottomside thickness parameter in order to modify the profile shape.

\subsubsection{Validation of the adaptation methods}

The latest technique developed to adapt NeQuick and IRI models to GPS and ionosonde data at a given location essentially tries to reproduce the experimental slab thickness (having TEC and $f o F 2$ ) of the ionosphere for the location of interest. Since many electron density profiles could have the same slab thickness, the 
correctness of the slab thickness itself does not imply the correctness of the electron density profile for the location considered. Therefore independent electron density values, (possibly complete profiles) are needed to validate the proposed adaptation method. In this respect, data obtained from the Incoherent Scatter Radar at the Jicamarca Radio Observatory (JRO) have been used for a preliminary validation, as they represent electron density profiles that could reach heights well above $1000 \mathrm{~km}$.

As a first step, no GPS or ionosonde data were considered, but JRO profiles were used directly to simulate the process of adapting NeQuick and IRI to GPS derived TEC and ionosonde peak parameters data. In fact TEC and peak parameters values are known from the profile and after the models adaptation it is possible to compare the retrieved and the experimental profiles in order to evaluate the adaptation technique effectiveness.

JRO 20060920 UT: 19.43

Exp Std Tec F2 peak F2 peak \& TEC

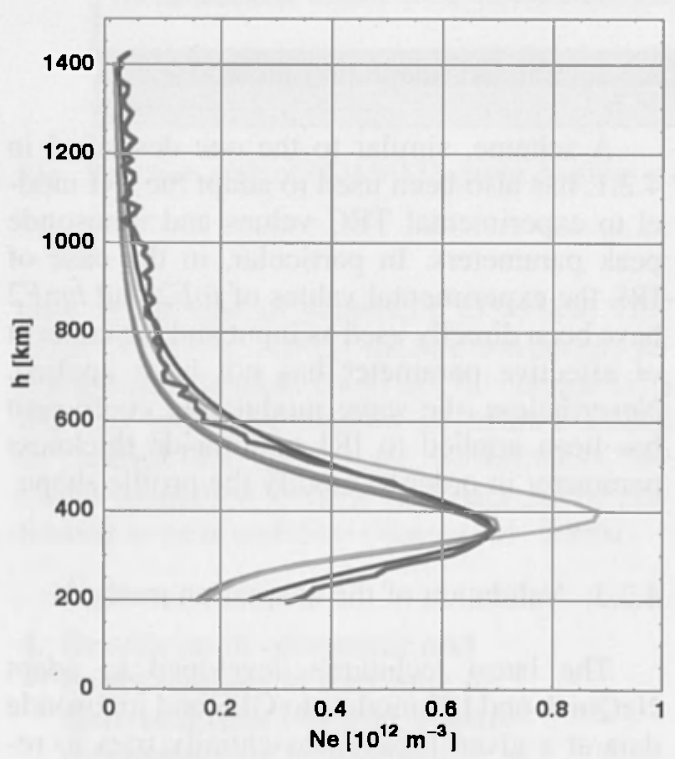

As an example, the first results concerning the application of this near-real-time electron density retrieval technique to NeQuick and IRI model are illustrated in the left and right panels of fig. 9 respectively. In particular the figure shows the electron density profiles at Jicamarca for the day 20 Sep 2006 at 19.43 UT. The experimental values are plotted in red. The yellow profiles are obtained with the models driven by the flux of the day. The light blue profiles are obtained adapting the models to experimental TEC only. The green profiles are obtained adapting the models to experimental foF 2 and $h m F 2$. The blue profiles are obtained with NeQuick and IRI adapted to experimental TEC, $f \circ F 2$ and $h m F 2$. The figures show the effectiveness of the proposed adaptation scheme in terms of vertical electron density profile reconstruction, regardless of the model used to implement it. Indeed, the best results are obtained when the models are adapted to experimental

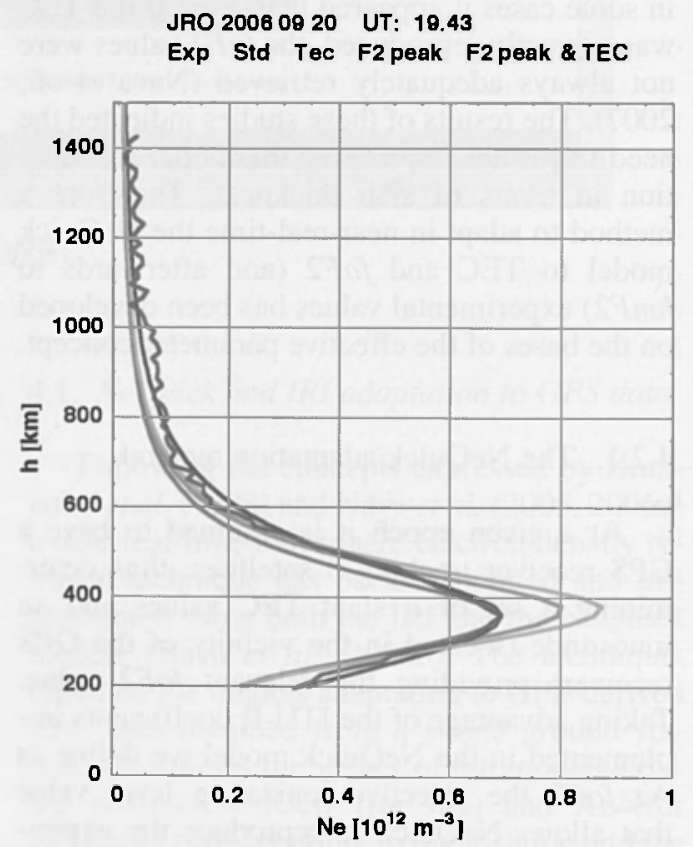

Fig. 9. Electron density profiles at Jicamarca for the day 20 Sep 2006, 19.43 UT. Left panel: NeQuick-modelled profiles. Right panel: IRI-generated profiles. Red curves: experimental values. Yellow curves: models driven by the flux of the day. Light blue curves: models adapted to experimental TEC. Green curves: models adapted to experimental foF 2 and $h m F 2$. Blue curves: models adapted to experimental TEC, foF2 and $h m F 2$. 
TEC, foF2 and $h m F 2$ data and are similar for both NeQuick and IRI.

In addition, the proposed adaptation scheme also indicates a possible strategy to improve the analytical formulation of the model. For example it is possible to separate the contribution of the bottomside and the topside in order to have a modulating coefficient for each part of the model profile.

\subsection{Raytracing through a tilted ionosphere}

Digisonde Doppler skymaps are now processed to determine zenith and azimuth angles of the ionospheric horizontal tilt, thus increasing accuracy of the HF raytracing (Huang and Reinisch, 2006). Real-time information on the ionospheric tilt is available from those digisondes that record skymaps after each ionogram. In combination with the vertical profile derived automatically from the ARTIST-scaled ionogram, the local tilt from the skymaps is used to derive the 3-D Ne distribution representing the instantaneous ionosphere structure near the site. The characteristics of each layer, e.g., critical frequencies and peak heights, are expressed as a function of latitude $\lambda$ and longitude $\psi$. In the neighbourhood of the sounder site each characteristic, e.g., foF 2 , is given as:

$$
\begin{aligned}
f o F 2(\lambda, \psi)= & f o F 2 m\left(1+C_{7} \Delta \lambda+C_{8} \Delta \psi\right) \\
& \left(1+C_{\lambda} \Delta \lambda+C_{\psi}, \Delta \psi\right)
\end{aligned}
$$

The coefficients $C_{7}$ and $C_{8}$ for any given azimuth direction are determined with the use of the URSI/CCIR coefficients (that are also used in IRI), and the calculation of $C_{\lambda}$ and $C_{\psi}$ makes use of the measured ionospheric tilt data as described by Huang and Reinisch (2006); foF $2 \mathrm{~m}$ is the local, measured foF 2 value. Raytracing through simulated tilts shows that the differences in ground distances for one hop high frequency (HF) propagation vary from about $1 \mathrm{~km}$ to $100 \mathrm{~km}$ depending on the assumed tilts and distances. Operational tests for distances up to approximately $100 \mathrm{~km}$ have demonstrated good results in determining the transmitter location in real time, and have illustrated the importance of using the actual ionospheric profiles and tilts in the raytracing.

\subsection{Supporting real-time operations of digisonde network}

Along with the growing network of digisonde contributing their real-time data to the space weather systems come increased overheads of maintaining healthy operations of the network. Special attention has been paid to the task of rapid automatic detection of the data quality problems in order to reduce the demand for manual inspection of the data traffic from $\sim 35$ digisondes. A new quality control system based on the Lowell DIDBase became operational in 2005 . The system is capable of detecting data gaps due to failures in remote communications and various system malfunctions that result in blank ionograms or poor quality of autoscaling.

\subsection{Regional Total Electron Content modelling/forecasting with geomagnetic activity corrections}

Regional TEC mapping is usually assisted by empirical models to yield better results in areas of irregular/sparse measurements. The approach, using the European regional TEC model NTCM (Jakowski, 1996), was used for years utilising GPS measurements from the International GPS Service (IGS) network.

High resolution GPS data allow the determination of slant TEC values along numerous satellite-receiver links over Europe. After calibration, the slant TEC data are mapped to the vertical by applying a mapping function based on a single ionospheric layer approximation set at an altitude of $400 \mathrm{~km}$. Afterwards, the measurements are assimilated into the NTCM model in which the TEC value is expressed as a function of time. latitude, season, and solar activity.

The model coefficients are estimated via least square fitting to a large measurement data set and are regularly updated in line with the changing solar activity.

The above-described modeling procedure en- 

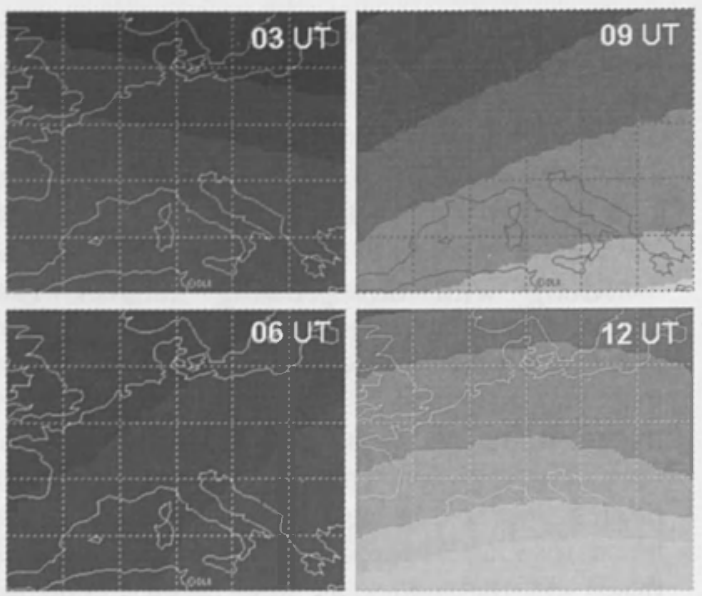
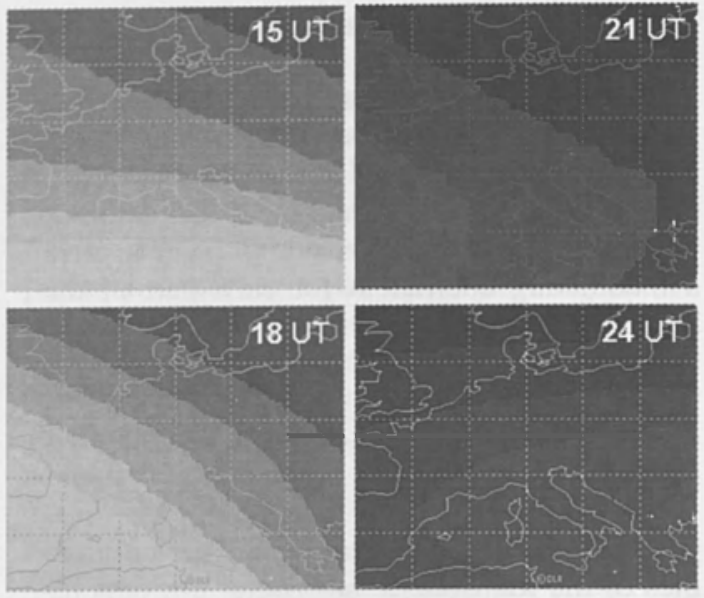

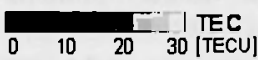

Fig. 10. European TEC forecast (1 hour lead time) based on the NTCM use and the quiet-time geomagnetic activity correction for 3 October $2006(1.0<K p<2.67)$.

sures that the final TEC map provides the real measurement values at the observation points and model values over areas void of observations.

Recently, during the space weather project SWACI (Jakowski et al., 2005; 2006), the NTCM model has played another role.

TEC short-term forecast maps have been obtained by predicting the TEC median (geomagnetically-quiet time) behaviour using the latest TEC value obtained from real-time GPS measurements and assuming the future TEC gradient estimated by the NTCM model. In addition, an immediate correction of this median forecast is made, taking into account the geomagnetic activity influence.

TEC is known to depend on the geomagnetic activity and to deviate from its median even during quiet conditions $\left(K_{p}<4\right)$.

Deviations exceeding $10 \%$ are possible, particularly at higher latitudes (Jodogne and Stankov, 2002). To better account for such variability, a synthetic index capturing the averaged response of the TEC value has been developed. Essentially, the index is an approximation of the averaged normalized behaviour of TEC at each geomagnetic level of activity. By assuming that the geomagnetic activity is the sole cause of the TEC deviation from median at a certain location, the average behaviour of the above deviations can be presented as a function of the planetary geomagnetic index $K_{p}$ (alternatively, the $A_{p}$ index):

$$
\Theta(\varphi, \lambda, \mu)=\sum_{i=0}^{3} c_{i}(\varphi, \lambda, \mu) \cdot K_{p}^{i}
$$

depending on month of year $(\mu)$, geomagnetic latitude $(\phi)$ and longitude $(\lambda)$ of the location.

The polynomial coefficients for the sites of the European ionosonde stations have been obtained from data covering the majority of the recent solar cycle (Stankov and Jakowski, 2006).

TEC forecast maps, corrected with the help of this synthetic index, are presented in fig. 10 .

The TEC relative deviation from the median is strongly influenced by the storm time elapsed (i.e. the time elapsed from the storm onset) and the influence depends substantially on latitude and season (Stankov and Jakowski, 2007). A procedure for European TEC map correction, based on the TEC average storm-time deviation, is currently being developed and will be reported in a follow-on publication. 


\subsection{Effectiveness of the IRI-2001-predicted $N(h)$ profile updating with real-time measurements}

The analysis of the IRI 2001 model capability to reconstruct the state of ionospheric ionization under quiet and disturbed conditions and the analysis of the effectiveness of the IRI 2001 -predicted $N(h)$ profile updating with realtime measurements have been continued. Selected European ionosondes data (parameters $N m F 2$ and $h m F 2$ ) for 2004 and those of the model have been compared.

The results of our analysis shows that IRI model calculations are in worse agreement with observations especially during daytime hours at the ionospheric heights from 200 to $400 \mathrm{~km}$.

The disagreement between IRI 2001 model calculations and measured values increases mainly under disturbed conditions (Buresova et al., 2006). Similar findings were obtained comparing radio propagation parameters generated by a $2 \mathrm{D}$ ray tracing software abcray 03 with those predicted by IRI 2001 and NeQuick models.

Therefore, updating the IRI model with the near-real time measured ionospheric parameters introduces actual corrections and makes the resulting $N(h)$ profile more realistic. However, there still exist some limitations of the method. A limitation in the accuracy of the method itself, similar to the case of the method based on SIRM updating (Zolesi et al., 2004), comes from performance of the automatic scaling algorithm ARTIST under certain conditions (e.g. interference in the ionogram trace).

In such cases, ARTIST fails to scale the ionograms correctly, leading to an error in the main parameters (Buresova et al., 2007) However, since the inputs are taken from several reference stations, the contribution of individual errors to the total result is expected to be small (it means, that the quality of the updated maps depends on the number of ionospheric stations that can provide the actual $N(h)$ profiles). In addition, new ARTIST 5 version eliminates many of the weak points of the previous version, especially with regard to the handling of the trace gaps and $F 2$ trace truncations (Reinisch et al., 2005).

\section{Acknowledgements}

We acknowledge support by COST. D. Buresova thanks Ministry of Education, Youth and Sports of the Czech Republic for support of Czech participation in COST 296 through grant OC-091. This research is being supported by the German State Government of MecklenburgVorpommern under grant AU 07 008. S. M. Stankov acknowledges also the financial support of the Royal Meteorological Institute of Belgium via grant GJU/06/2423/CTR/GALO$\mathrm{CAD}$ and the RMI Centre of Excellence. SWACI has been funded by the German State Government of Mecklenburg and Western Pomerania under grant V230-630-08-TIFA334. EDAM has been developed under funding from the Operating Environment domain of the United Kingdom. K. Ministry of Defence Corporate Science and Technology programme. IGS data was obtained from the IGS JPL and SOPAC Data Centres. Differential code biases were obtained from the Centre for Orbit Determination in Europe. This work has been partially supported via grant 205/08/1356 of the Grant Agency of the Czech Republic. The authors are also grateful to the Jicamarca Radio Observatory (IRO) group and Luigi Ciraolo of IFAC for providing some of the data used in the present study. We would like also acknowledging $\mathrm{R}$. Leitinger, T. Gulyaeva, H. Rothkaehl. L. Ciraolo, B. De la Morena, and N. Jakowski for their contribution to the results of the WP1.2. Vertical ionosonde data was provided by the Air Force Research Laboratory.

\section{REFERENCES}

ANGLING, M.J. and P.S. CANNON (2006): On the development, testing and exploitation of an ionospheric data assimilation system, Paper presented at IET IOth Conference on Ionospheric Radio Systems and Techniques. (London).

ANGLiNG, M.J. and B. KhatTatov (2006): Comparative study of two assimilative models of the ionosphere, $R a$ dio Sci., 41, RS5S20, doi: 10.1029/2005RS003372.

ANGLING, M.J. (2008a): On the testing of the electron density assimilative model (EDAM) with a data from a globally distributed network ionosondes. Paper presented at the European Geophysics Union Symposium. (Vienna).

ANGLING. M.J. (2008b): First assimilations of COSMIC ra- 
dio occultation data into the Electron Density Assimilative Model (EDAM), Ann. Geophysicae., 26, 353-359.

ANGling, M.J., J. Shaw, A.K. Shukla and P.S. Cannon (2008): Development of an HF frequency selection tool based on the EDAM real time ionosphere, Paper presented at Ionospheric Effects Symposium, (Alexandria, USA).

Araujo-Pradere, E.A, T.J. Fuller-Rowell and M.V. CoDRESCU (2002): STORM: An empirical storm-time ionospheric correction model - 1. Model description, Radio Sci., 37 (5), doi:10.1029/2001RS002467, 3.1-12.

Blanch, E., D. Arrazola, D. Altadill, D. Buresova and M. MOSERT (2007): Improvement of IRI B0, BI and DI at mid-latitude using MARP, Adv. Space Res., 39, $701-710$

Buresova, D., LJ. R. Cander, A. Vernon and B. Zoles (2006): Effectiveness of the IRI-2001-predicted N(h) profile updating with real-time measurements under intense geomagnetic storm conditions over Europe, $A d v$. Space Res., 37, 1061-1068.

Buresova, D., V. Kraskov, YA. Drobzheva, J. LastoviCKA, J. CHUM and F. HRUSKA (2007): Assessing the quality of ionogram interpretation using HF Doppler technique, Ann. Geophysicae., 25, 895-904.

Buresova, D., L-A. McKinnell, T. Sindelarova, I. BlanCo ALEGRE and B. De LA Morena (2008): Evaluation of the STORM model storm-time corrections for middle latitudes, Invited paper presented at 37th COSPAR Scientific Assembly, (Montreal, Canada).

Coisson, P., S.M. Radicella, B. Nava and R. Leitinger (2006): Topside electron density in IRI and NNeQuick: features and limitations, Adv. Space Res. 37 (5), 937 942.

Di Giovanni, G. and S.M. Radicella (1990): An analytical model of the electron density profile in the ionosphere, Adv. Space Res., 10 (11), 27-30.

DUDENEY, J.R. (1983): The accuracy of simple methods for determining the height of the maximum electron concentration of the $F$ 2-layer from scaled ionospheric characteristics, J. Atmos. Solar-Terrll Phys., 45, 629-640.

Galkin, I.A., G.M. KhMYrov, A. Kozlov, B.W. ReinisCh, X. HuANG and D.F. Kitrosser (2006): Ionosonde networking, databasing, and web serving, Radio Sci., 41 (5), RS5S33, doi:10.1029/2005RS003384.

Galkin, I.A., G.M. KhMyrov, A. Kozlov, B.W. ReinisCH, X. HuANG and V.V. PAzNukhov (2008a): The ARTIST 5, Radio Sounding and Plasma Physics, AIP Conf. Proc., 974, 150-159.

Galkin, I.A., G.M. KhMYrov, B.W. ReinisCh and J. MCELROY (2008b): The SAOXML 5, New format for ionogram-derived data, Radio Sounding and Plasma Physics, AIP Conf. Proc., 974, 160-166.

Hochegger, G., B. Nava, S.M. Radicella and R. LEITINGER (2000): A family of ionospheric models for different uses, Phys. Chem. Earth, 25 (4), 307-310.

Huang, X. and B.W. Reinisch (2006): Real time HF raytracing through a tilted ionosphere, Radio $S c i ., 41$ (5), RS5S47, doi: 10.1029/2005RS003378.

JAKOWSKI, N. (1996): TEC Monitoring by Using Satellite Positioning Systems, in Modern Ionospheric Science. European Geophysical Society, edited by H. KOL, R. RUESTER and K. SCHLEGEL, (Katlenburg-Lindau), 371-390.

Jakowski, N., S.M. Stankov, D. KlaEhn, C. Becker, C.
Mayer, J. Rueffer, B. Huck, A. Rietdorf, C. Daub, G. Weber and M. Meier (2005): Operational space weather service for regional GNSS based applications, Proc. US Space Weather Week, 5-8 April 2005, (Boulder, USA).

Jakowski, N., H. MaAss, S.M. Stankov, K.D. Missling, C. BeCKer, C. MAYer, M. Hoque, V. Rudenko and M. TEGLER (2006): SWACI - Space weather service for high precision GNSS positioning, Proc. Third European Space Weather Week ESWW-2006, 13-17 Nov 2006, (Brussels, Belgium).

JoDOGNE, J.C. and S.M. STANKOV (2002): Ionosphere-plasmasphere response to geomagnetic storms studied with the RMI-Dourbes comprehensive database, Ann. of Geophys. 45 (5), 629-647.

Khattatov, B., M. Murphy, M. Gnedin, B. Cruickshank, J. ADAMS, V. YUdin and T. Fuller-Rowell (2004): Ionospheric Corrections from a Prototype Operational Assimilation and Forecast System, Proceedings of IEEE Position, Location, and Navigation Symposium, (PLANS), (Monterrey, CA, April 26-29).

Khattatov, B., M. Gnedin, M. Murphy, B. Cruickshank, J. AdAMS, V. Yudin, T. FUller-Rowell, J.W. WROGHT, N.A. ZABOTIN and M.J. ANGLING (2005): An AFRL sponsored ionospheric specification system, Proceedings of the Ionospheric Effects Symposium, (Alexandria, USA).

Khmyrov, G.M., I.A. Galkin, A.V. Kozlov, B.W. ReINISCH, J. McElroY and C. Dozols (2008): Exploring digisonde ionogram data with SAO-X and DIDBase, Radio Sounding and Plasma Physics, AIP Conf. Proc., 974, 175-185.

KomjathY, A., R.B. LANGLEY and D. BILITZa (1998): Ingesting GPS- derived TEC data into the International Reference Ionosphere for single frequency radar altimeter ionospheric delay corrections, Adv. Space Res., 22, 793-801.

LEITINGER, R., M.L. ZHANG and S.M. RADICELla (2005): An improved bottomside for the ionospheric electron density model NeQuick, Ann. of Geophys., 48 (3), 525534.

Nava, B., P. Coisson, G. Miro Amarante, F. Azpilicueta and S.M. RADICELla (2005): A model assisted ionospheric electron density reconstruction method based on vertical TEC data ingestion, Ann. of Geophys., 48 (2), 313-320.

Nava, B., S.M. Radicella, R. Leitinger and P. Coisson (2006a): A near-real time model-assisted ionosphere electron density retrieval method., Radio Sci., 41. RS6S16.

Nava, B., S.M. Radicella and P. Coisson (2006b): TEC data ingestion in IRI and NeQuick ionosphere electron density models, Proceedings of the COST 296 Workshop on Radio Systems and Ionospheric Effects, (Rennes, 3-7 October).

Nava, B., S.M. Radicella, R. Leitinger and P. Coisson (2007): Use of slab thickness to improve the NeQuick electron density profile formulation, Proceedings of the International Beacon Satellite Symposium, (Boston College, June 11-15).

Nava, B.. P. Coisson and S.M. Radicella (2008): A new version of the NeQuick ionosphere electron density model, $J$. Atmos. Solar-Terr: Phys., doi:10.1016/j.jastp.2008.01.015. 
RADICELLA, S.M. and M.L. ZHANG (1995): The improved DGR analytical model of electron density height profile and total electron content in the ionosphere, Annali di Geofisica, 38 (1), 35-41.

RADicella, S.M. and R. LeITINGER (2001): The evolution of the DGR approach to model electron density profiles, Adv. Space Res., 27 (1), 35-40.

ReinisCH, B.W. and X. HuANG (1983), Automatic calculation of electron density profiles from digital ionograms, 3, Processing of bottomside ionograms, Radio Sci., 18, 477-492.

Reinisch, B.W., X. Huang, I.A. Galkin, V. Paznukhov and A. KozLov (2005): Recent advances in real-time analysis of ionograms and ionospheric drift measure- ments with digisondes, J. Atmos. Solar-Terr. Phvs., 67 (12), 1054-1062.

STANKOV, S.M. and N. JAKOWSKI (2006): Indexing the local ionospheric response to magnetic activity by using total electron content measurements, Acta Geod. Geoph. Hung., 41 (1), 1-15.

STANKOV, S.M. and N. JAKOWSKI (2007): Ionospheric effects on GNSS reference network integrity. J. Atmos. Solar-Terr: Phys., 69 (4-5), 485-499.

Zolesi, B., A. Belehaki, I. TSagouri and LJ.R. Cander (2004): Real-time updating of the Simplified Ionospheric Regional Model for operational applications, Radio Sci., 39, RS2011. 